\title{
Microbiological and lipolytic changes in high-pressure-treated raw milk cheeses during refrigerated storage
}

\author{
Joaquín Rodríguez-Pinilla • Gracia Márquez • \\ Rafael Tabla $\cdot$ Rosario Ramírez • \\ Francisco José Delgado
}

Received: 12 November 2014 / Revised: 6 February 2015 / Accepted: 19 February 2015 /

Published online: 19 March 2015

(C) INRA and Springer-Verlag France 2015

\begin{abstract}
High-pressure processing (HPP) has been used to control microorganisms and enzymes and avoid over-ripening in cheese. Excessive lipolysis is associated with over-ripening in cheese. However, little information about the effect of high pressure on microorganisms and lipolysis in mature cheese is available. For this reason, microbiological and lipolytic changes during refrigerated storage of pressurised Torta del Casar cheese (a raw ewe's milk cheese) were studied. Mature cheeses (60 days of ripening) were high-pressure treated ( 200 or $600 \mathrm{MPa}$ for 5 or $20 \mathrm{~min}$ ) and stored at $6{ }^{\circ} \mathrm{C}$. Cheese samples were analysed at day 60, just after high-pressure treatment, and during the refrigerated storage (at days 120, 180 and 240). Enterobacteriaceae counts were significantly reduced after high-pressure treatment, thus increasing the food safety of this cheese. In particular, Enterobacteriaceae showed a significant $(p<0.01)$ decrease of 2.18 and $2.46 \log$ units in cheeses treated at $200 \mathrm{MPa}$ for $20 \mathrm{~min}$ at days 120 and 180 , respectively; however, treatment at $600 \mathrm{MPa}$ for $20 \mathrm{~min}$ only caused reductions of 2.09 and $1.79 \log$ units at days 120 and 180 . Free fatty acids content was not significantly influenced by high-pressure treatment, although it increased with time of storage.
\end{abstract}

Keywords Raw ewe milk cheese $\cdot$ High pressure $\cdot$ Free fatty acids $\cdot$ Microbiology Refrigerated storage

\section{Introduction}

During cheese ripening, biochemical and microbiological changes are responsible for the development of cheese flavour and texture. Lipolysis involves the release of free

\footnotetext{
J. Rodríguez-Pinilla $\cdot$ G. Márquez $\cdot$ R. Tabla $\cdot$ R. Ramírez $\cdot$ F. J. Delgado

Centro de Investigaciones Científicas y Tecnológicas de Extremadura (CICYTEX), Badajoz, Spain

J. Rodríguez-Pinilla $\cdot$ G. Márquez $\cdot$ R. Tabla $・$ R. Ramírez $\cdot$ F. J. Delgado $(\bowtie)$

Instituto Tecnológico Agroalimentario de Extremadura (INTAEX) (Technological Agri-Food Institute),

Avda. Adolfo Suárez s.n., 06071 Badajoz, Spain

e-mail: fjdmartinez@yahoo.es
} 
fatty acids (FFAs) from triglycerides by the action of lipases. This is the most important pathway for the development of flavour (Collins et al. 2003). Lipolysis has been studied intensively in blue and hard Italian cheeses in which lipolysis reaches high levels. In cheeses made from raw ewe's milk, lipolytic changes during ripening have been studied in semi-hard Idiazábal cheese (Hernández et al. 2009) as well as in other cheeses in which vegetable rennet is used such as La Serena cheese (Fernández-García et al. 2006), Serra da Estrella cheese (Partidario et al. 1998; Macedo and Malcata 1996) and Torta del Casar cheese (Delgado et al. 2009).

High-pressure (HP) treatment or high-pressure processing (HPP) is a "cold pasteurisation" method of food preservation used for a wide range of products to ensure their microbiological safety and extend their shelf life. HPP also maintains the sensorial and nutritional properties of food (Balasubramaniam et al. 2008). In the last years, HP technology applied to cheese processing has been focused on two main areas: microbiological safety and modification of the ripening process (Martínez-Rodríguez et al. 2012). In raw milk cheeses, several studies have reported a complete inactivation of pathogenic microorganisms when HP treatment is combined with bacteriocins (Rodríguez et al. 2005; Arqués et al. 2005a, b). Furthermore, studies in La Serena cheese have found that treatments at $400 \mathrm{Ma}$ for $10 \mathrm{~min}$ at day 2 of ripening significantly reduced the levels of microorganisms at day 30 of ripening and caused the complete inactivation of coagulase-positive staphylococci (Arqués et al. 2006).

On the other hand, limited information is available on the effect of HP treatment on the lipolysis of cheese. In ewe's milk cheese, HP treatment at $300 \mathrm{MPa}$ applied on the first day of ripening increased the lipolytic process, but pressures $\geq 400 \mathrm{MPa}$ decelerated the lipolysis (Juan et al. 2007a). These authors have reported that cheeses treated at $300 \mathrm{MPa}$ on the first day of ripening showed high levels of medium-chain and longchain FFAs after 60 days of ripening. This result was attributed to a faster release of intracellular enzymes into the cheese induced by HP treatments. Moreover, high levels of short-chain FFAs were found in cheeses treated at $300 \mathrm{MPa}$ at day 15 of ripening (Juan et al. 2008). Recently, Calzada et al. (2014) have reported that HP treatment could be applied to decelerate the lipolysis during ripening and storage of Torta del Casar cheese in order to prolong its shelf life and prevent the over-ripening. However, HP treatments (400 or $600 \mathrm{MPa}$ for $5 \mathrm{~min}$ ) were carried out during cheese ripening (day 21 or 35). This fact could be problematic because the rules of the Protected Designation of Origin (PDO) may not allow the cheese processing during their ripening. As stated above, several studies have demonstrated that HPP during cheese ripening causes different changes in cheese lipolysis (Juan et al. 2007a, 2008; Calzada et al. 2013, 2014). For these reasons, the application of HPP at the end of cheese ripening (day 60) could be a more convenient procedure. In addition, cheese could be placed on the market vacuum packaged and just after HP treatment ("ready to be sold").

In these cheeses made from raw ewe's milk in which cardoon is used as coagulant, the main lipolytic agents are indigenous milk lipases (lipoprotein lipase) and lipases from microorganisms. These cheeses, due to the fact that no starter cultures are used, have high $\mathrm{pH}$ values at early stages of ripening, high moisture and low salt content, which favours the growth of contaminating microorganisms (Fernández del Pozo et al. 1988) causing excessive lipolysis depend on the contaminant and the development of rancid flavours during cheese ripening and storage. Changes in cheese taste and odour are associated with an excess of FFAs and/or to the enhancement of the lipolytic 
reactions in cheese (McSweeney and Sousa 2000; Collins et al. 2003). HPP offers the possibility of modifying the ripening routes of cheese (Martínez-Rodríguez et al. 2012). The effects of this treatment could be desirable in some cases and retard or arrest some ripening routes. In this case, microbiological and lipolytic changes are two important ripening parameters that may be modified after HPP and this fact could affect the final quality of this cheese. Therefore, the main objective of this work was to study the microbiological and lipolytic changes after the application of HPP on the mature "Torta del Casar" cheese and their evolution during the refrigerated storage (vacuum-packaged cheeses) in order to know the effect of this treatment on the shelf life of this cheese variety.

\section{Materials and methods}

\subsection{Material and experimental design}

The cheeses were manufactured in a dairy from the Protected Designation Origin Torta del Casar. No starter cultures were added, and vegetable rennet obtained from the flowers of the Cynara cardunculus thistle was used. The vegetable coagulant for cheesemaking was prepared using $500 \mathrm{~g}$ of dry flowers from $C$. cardunculus, ground in a mortar and soaked in tap water $(10 \mathrm{~L})$ at room temperature for $24 \mathrm{~h}$ and filtered through a cheese cloth. Approximately $1,000 \mathrm{~L}$ of milk was heated to $30^{\circ} \mathrm{C}$, and coagulation took place after $60 \mathrm{~min}$. The curd was cut and then transferred into suitable moulds, where it was pressed for $4 \mathrm{~h}$ at pressure $1-2.5 \mathrm{~kg} . \mathrm{cm}^{-2}$. After that, cheeses were submerged in brine (sodium chloride 14-16\% $w / v ; \mathrm{pH} 5.5-5.7$ ) for $\sim 4 \mathrm{~h}$. Afterwards, cheeses were ripened for 60 days (at $4-10{ }^{\circ} \mathrm{C}$ and $80-90 \%$ relative humidity). The physicochemical properties of 60 -day-old cheeses were $5.8 \mathrm{of} \mathrm{pH}$, $52 \%$ of fat content in dry matter, $58 \%$ of dry matter and $1.5 \% \mathrm{NaCl}$.

A total of 80 cheeses with 60 days of ripening were high-pressure treated at four different conditions. Then, a part of the cheeses was sampled and the others were stored at refrigerated conditions until cheeses had 120, 180 or 240 days. Cheeses were sampled at days 60, 120, 180 and 240. Control cheeses (non-pressurised cheeses) were analysed in each sampling day. Therefore, a total of 80 cheeses were analysed in this study ( 5 treatments $\times 4$ times of storage $\times 4$ cheeses per batch).

\subsection{Hydrostatic high-pressure processing}

Cheeses were vacuum packaged in flexible polyethylene plastic bags $\left(9.3 \mathrm{~mL} \mathrm{O} \mathrm{O}_{2} / \mathrm{m}^{2}\right.$ / $24 \mathrm{~h}$ at $0{ }^{\circ} \mathrm{C}$ ) by using a vacuum packaging machine (ILPRA, UM 18-GAS DIG., Barcelona, Spain), for the application of the high-pressure treatments. Cheeses were processed in a semi-industrial high-pressure unit of Hiperbaric (Wave 6000/55, Hiperbaric, S.A., Burgos, Spain). Two pressures intensities $(200$ or $600 \mathrm{MPa}$ ) and two holding times (5 or $20 \mathrm{~min}$ ) were applied. Water was utilised as pressuretransmitting medium. The time taken to reach the target pressure was 110 and $230 \mathrm{~s}$, and decompression took place in 1-2 s. The initial temperature of water in the highpressure vessel was $10^{\circ} \mathrm{C}$. After processing, some cheeses were sampled and the others were stored to evaluate their evolution during the storage. 


\subsection{Refrigerated storage}

Vacuum-packaged cheeses were stored at $6{ }^{\circ} \mathrm{C}$ for 180 days to simulate the conditions of a supermarket. From each cheese, samples for FFA analysis were taken from the inner part of the cheese and were stored at $-80{ }^{\circ} \mathrm{C}$ until they were analysed. Before freezing, samples from the rind and from the inner part were taken for the microbiological analysis.

\subsection{Microbiological analysis}

Ten grams of each sample was collected into sterile sample bags (Cole Palmer, Chicago, IL, USA) and homogenised with sterile $2 \%(w / v)$ sodium citrate (Panreac, Barcelona, Spain), at $45^{\circ} \mathrm{C}$ for $5 \mathrm{~min}$, using a dilution factor $1: 10(w / v)$ in a Stomacher 400 Circulator (Seward, London, UK). Decimal dilutions were prepared in sterile $0.1 \%$ $(w / v)$ peptone water (Sigma, St. Louis, MO, USA). From each dilution, $1 \mathrm{~mL}$ volumes were pour plated in duplicate, using Plate Count Agar (PCA) (Scharlab, Barcelona, Spain) for total mesophilic bacteria counts. Pseudomonas spp. were grown on Cetrimide Agar (Merck, Darmstadt, Germany) containing $1 \%(v / v)$ glycerol. Moulds were grown on Rose Bengal Chloramphenicol Agar (RB) (Oxoid Ltd, Basingstoke, UK). Enterobacteriaceae were determined on Violet Red Bile Glucose Agar (VRBGA). After mixing and solidifying, PCA plates were incubated aerobically at $30{ }^{\circ} \mathrm{C}$ for $72 \mathrm{~h}$, Cetrimide and $\mathrm{RB}$ plates were incubated at $25{ }^{\circ} \mathrm{C}$ for 5 days and VRBGA plates were incubated at $37^{\circ} \mathrm{C}$ for $24 \mathrm{~h}$. Plates with 20-200 colonies were counted, and results were expressed as log colony-forming units per gram.

\subsection{Free fatty acids content}

FFAs were extracted according to the modified method of De Jong and Badings (1990) as described by Delgado et al. (2009). The lipid extract was fractionated using an aminopropyl column (AccuBond ${ }^{\mathrm{II}}$ SPE, Agilent Technologies, UK). FFAs were eluted with diethyl ether containing $2 \%$ formic acid. A direct injection of this solution $(1 \mu \mathrm{L})$ was used for gas chromatograph analysis. For each sample, two extractions of FFAs were carried out. FFAs extracted were analysed in a HP 6890 gas chromatograph (Agilent Technologies, USA) equipped with a HP 7683 injector, a FFAP column (Agilent Technologies, $30 \mathrm{~m} \times 0.25 \mathrm{~mm}$ ID $\times 0.25 \mu \mathrm{m}$ film thickness) and a FID detector. Chromatographic conditions were as follows: initial $\mathrm{T} 50{ }^{\circ} \mathrm{C}$ holds $1 \mathrm{~min}$, up to a final $\mathrm{T}$ of $240{ }^{\circ} \mathrm{C}$ holds $20 \mathrm{~min}$ at $5{ }^{\circ} \mathrm{C} \cdot \mathrm{min}^{-1}$. Helium flow was set at $2 \mathrm{~mL} \cdot \mathrm{min}^{-1}$ and the split ratio at 1:10. For each fatty acid, a suitable regression curve was calculated by analysing increasing amounts of individual fatty acids (SigmaAldrich, Madrid, Spain) with fixed amounts of internal standard. The sum of shortchain fatty acids (SCFA, C4:0-C8:0), medium-chain fatty acids (MCFA, C10:0-C14:0) and long-chain fatty acids (LCFA, C16:0, C18:0, C18:1 and C18:2) were calculated.

\subsection{Statistical analysis}

The significance of the effects of HPP and storage time was analysed using the one-way analysis of variance (ANOVA) procedure of SPSS, version 17.0 (SPSS Inc., Chicago, 
IL, USA). This analysis was applied twice: once for the evaluation of the effect of HPP (rows of the table) and the other one to evaluate the effect of the storage time (columns of the table). HSD Tukey's test was applied to compare the mean values when ANOVA showed significant differences.

\section{Results and discussion}

\subsection{Microbiological groups in HP-treated Torta del Casar cheese}

The counts of mesophilic bacteria, Pseudomonas spp. and moulds on the rind of Torta del Casar cheeses at days 120, 180 and 240 of refrigerated storage are shown in Table 1. Mesophilic bacteria were not affected by HPP at $200 \mathrm{MPa}$. Mesophilic microorganisms counts on the rind were significantly $(p<0.001)$ reduced by HP treatments at $600 \mathrm{MPa}$. The reduction was around 1.4 and $2.6 \log$ units in cheeses treated at day 60 at $600 \mathrm{MPa}$ for 5 and $20 \mathrm{~min}$, respectively, compared with control cheeses. When the evolution of the counts is evaluated during the storage, the counts were significantly reduced in all microbial groups (except in cheeses treated at $600 \mathrm{MPa}$ for $20 \mathrm{~min}$ ) at the end of

Table 1 Microbiological counts (log CFU.g $\left.{ }^{-1}\right)$ of mesophilic microorganisms, Pseudomonas and moulds in the rind of Torta del Casar after the application of different high-pressure treatments and during refrigerated storage (days 120, 180 and 240)

\begin{tabular}{|c|c|c|c|c|c|c|c|c|}
\hline & \multirow[t]{2}{*}{ Day } & \multirow[t]{2}{*}{ Control } & \multicolumn{2}{|l|}{$200 \mathrm{MPa}$} & \multicolumn{2}{|l|}{$600 \mathrm{MPa}$} & \multirow[t]{2}{*}{ SEM } & \multirow[t]{2}{*}{ Significance } \\
\hline & & & $5 \mathrm{~min}$ & $20 \mathrm{~min}$ & $5 \min$ & $20 \mathrm{~min}$ & & \\
\hline \multirow[t]{4}{*}{ Mesophilic } & 60 & $9.15^{\mathrm{a}, \mathrm{A}}$ & $9.01^{\mathrm{a}, \mathrm{A}}$ & $8.76^{\mathrm{a}, \mathrm{A}}$ & $7.71^{\mathrm{b}, \mathrm{A}}$ & $6.52^{\mathrm{c}}$ & 0.24 & $* * *$ \\
\hline & 120 & $7.98^{\mathrm{a}, \mathrm{B}}$ & $8.27^{\mathrm{a}, \mathrm{B}}$ & $8.11^{\mathrm{a}, \mathrm{B}}$ & $6.41^{\mathrm{b}, \mathrm{B}}$ & $5.54^{\mathrm{c}}$ & 0.25 & $* * *$ \\
\hline & 180 & $7.69^{\mathrm{a}, \mathrm{B}}$ & $7.88^{\mathrm{a}, \mathrm{C}}$ & $7.93^{\mathrm{a}, \mathrm{B}}$ & $6.22^{\mathrm{b}, \mathrm{B}}$ & $5.96^{\mathrm{b}}$ & 0.21 & $* * *$ \\
\hline & 240 & $7.63^{\mathrm{a}, \mathrm{B}}$ & $7.85^{\mathrm{a}, \mathrm{C}}$ & $7.40^{\mathrm{ab}, \mathrm{C}}$ & $6.62^{\mathrm{b}, \mathrm{B}}$ & $5.59^{\mathrm{c}}$ & 0.21 & $* * *$ \\
\hline Significance & & $* * *$ & $* * *$ & $* * *$ & $* * *$ & ns & & \\
\hline \multirow[t]{4}{*}{ Pseudomonas } & 60 & $5.78^{\mathrm{a}, \mathrm{A}}$ & $4.85^{\mathrm{ab}, \mathrm{A}}$ & $4.81^{\mathrm{ab}, \mathrm{A}}$ & $3.28^{\mathrm{bc}}$ & $1.87^{\mathrm{c}}$ & 0.35 & $* * *$ \\
\hline & 120 & $3.00^{\mathrm{B}}$ & $3.46^{\mathrm{BC}}$ & $3.50^{\mathrm{AB}}$ & 4.16 & 3.32 & 0.17 & ns \\
\hline & 180 & $3.69^{\mathrm{B}}$ & $3.81^{\mathrm{B}}$ & $3.94^{\mathrm{A}}$ & 4.21 & 3.97 & 0.14 & ns \\
\hline & 240 & $3.52^{\mathrm{a}, \mathrm{B}}$ & $2.94^{\mathrm{ab}, \mathrm{C}}$ & $2.29^{\mathrm{b}, \mathrm{B}}$ & $3.28^{\mathrm{ab}}$ & $2.79^{\mathrm{ab}}$ & 0.15 & $*$ \\
\hline Significance & & $* * *$ & $* * *$ & $* *$ & $*$ & ns & & \\
\hline \multirow[t]{4}{*}{ Moulds } & 60 & 4.14 & 4.16 & 2.74 & 2.09 & 1.75 & 0.34 & $*$ \\
\hline & 120 & 1.32 & 2.07 & 2.29 & 1.74 & 1.69 & 0.20 & $\mathrm{~ns}$ \\
\hline & 180 & 2.17 & 2.14 & $<2$ & $<1$ & $<1$ & - & - \\
\hline & 240 & $<1$ & $<1$ & $<1$ & $<1$ & $<1$ & - & - \\
\hline Significance & & - & - & - & - & - & & \\
\hline
\end{tabular}

Different letters $(a, b, c)$ in the same row indicate statistically significant differences. Different letters (A, B, C) in the same column indicate statistically significant differences (Tukey test $p<0.05$ )

$S E M$ standard error of mean, $n s$ non-significant differences

${ }^{*} p<0.05 ; * * p<0.01 ; * * * p<0.001$ 
refrigerated storage (day 240); but the levels of mesophilic microorganisms in cheeses treated at $600 \mathrm{MPa}$ were lower than in control and cheeses treated at $200 \mathrm{MPa}$.

Pseudomonas counts on rind showed significant differences due to HPP on day 60 $(p<0.001)$. Pseudomonas levels were not affected by pressurisation at $200 \mathrm{MPa}$; cheeses treated at $200 \mathrm{MPa}$ showed counts closer to control. However, control and cheeses treated at $200 \mathrm{MPa}$ showed significant differences for Pseudomonas spp. counts throughout storage time. On the other hand, treatments at $600 \mathrm{MPa}$ were only effective just after pressurisation at day 60. Pseudomonas spp. are aerobic microorganisms, and their reduction in control cheese could be linked to the vacuum packaging of cheese.

Mould counts in rind showed significant differences $(p<0.05)$ on day 60 due to the application of HPP. Treatments at $600 \mathrm{MPa}$ for 5 and 20 min resulted in mould counts on rind of 2.1 and $2.4 \mathrm{log}$ units lower than control cheeses, respectively, just after HP processing (day 60). At day 180, cheeses treated at $600 \mathrm{MPa}$ achieved mould counts that were below $1 \mathrm{log}$ unit. The vacuum packaging of Torta del Casar might solve microbiological problems of this cheese, since during the storage, reductions of most microbiological groups were found. However, we have also observed that during the storage, the rind turns a whitish colour that is not what the consumer expects for this product. In the case the HP treatment was applied at industrial level, it would be interesting to study packages suitable for the application of the HP treatment but with sufficient oxygen permeability to allow not having to remove it after processing and to continue with the same package used for HPP during the commercialization of cheese. This would avoid the changes in the colour of the rind.

On the other hand, pressurisation at $200 \mathrm{MPa}$ had no significant effect on mesophilic counts in the interior of Torta del Casar cheese (Table 2). However, mesophilic counts in cheese treated at $600 \mathrm{MPa}$ for 5 and $20 \mathrm{~min}$ were 3.5 and $4.1 \log$ units lower than control cheeses just after HPP (day 60). The differences found after processing were maintained until the end of the storage. At day 240, the treatments at $600 \mathrm{MPa}$ for 5 and 20 min resulted in a total viable count of 2.6 and 3.6 log units lower compared with control cheeses. Reductions of $1.3 \mathrm{log}$ units have been reported for total viable aerobic counts on day 60 of ripening in raw ewe's milk La Serena cheese treated at $400 \mathrm{MPa}$ for $10 \mathrm{~min}$ on day 50 of ripening (Arqués et al. 2006). Additionally, reductions of up to 5 log units were reported for total bacterial counts in ewe's milk cheeses treated at $400 \mathrm{MPa}$ for $10 \mathrm{~min}$ on the first day of ripening.

Enterobacteriaceae showed a significant $(p<0.01)$ decrease of 2.18 and $2.46 \log$ units at days 120 and 180, respectively, in the interior of Torta del Casar cheese treated at $200 \mathrm{MPa}$ for $20 \mathrm{~min}$ (Table 2). In general, treatments at $600 \mathrm{MPa}$ also caused a significant reduction of this group at days 120 and 180 . Reductions of 2.3 and $4.85 \log$ units have been reported for Gram-negative bacteria counts and coliform counts, respectively, on day 60 of ripening in raw ewe's milk La Serena cheese treated at $300 \mathrm{MPa}$ for $10 \mathrm{~min}$ on day 50 of ripening (Arqués et al. 2006). Treatment at $300 \mathrm{MPa}$ for 10 min applied to ewe's milk cheese resulted in a reduction $>3 \log$ units of Enterobacteriaceae counts (Juan et al. 2004).

\subsection{Free fatty acids in HP-treated Torta del Casar cheese}

Short-chain fatty acid (SCFA, C4:0 to C8:0), branched-chain fatty acid (BCFA) (iC4:0, iC5:0), medium-chain fatty acid (MCFA, C10:0 to C14:0) and long-chain fatty acid 
Table 2 Microbiological counts (log CFU.g ${ }^{-1}$ ) of mesophilic microorganisms and Enterobacteriaceae in the interior of Torta del Casar after the application of different high-pressure treatments and during refrigerated storage (days 120, 180 and 240)

\begin{tabular}{|c|c|c|c|c|c|c|c|c|}
\hline & \multirow[t]{2}{*}{ Day } & \multirow[t]{2}{*}{ Control } & \multicolumn{2}{|l|}{$200 \mathrm{MPa}$} & \multicolumn{2}{|l|}{$600 \mathrm{MPa}$} & \multirow[t]{2}{*}{ SEM } & \multirow[t]{2}{*}{ Significance } \\
\hline & & & $5 \mathrm{~min}$ & $20 \mathrm{~min}$ & $5 \mathrm{~min}$ & $20 \mathrm{~min}$ & & \\
\hline \multirow[t]{4}{*}{ Mesophilic } & 60 & $9.17^{\mathrm{a}, \mathrm{A}}$ & $9.10^{\mathrm{a}, \mathrm{A}}$ & $9.00^{\mathrm{a}, \mathrm{A}}$ & $5.69^{\mathrm{b}}$ & $5.08^{\mathrm{b}}$ & 0.43 & $* * *$ \\
\hline & 120 & $8.87^{\mathrm{a}, \mathrm{AB}}$ & $8.83^{\mathrm{a}, \mathrm{B}}$ & $8.70^{\mathrm{a}, \mathrm{BC}}$ & $5.35^{\mathrm{b}}$ & $4.85^{\mathrm{b}}$ & 0.42 & $* * *$ \\
\hline & 180 & $8.73^{\mathrm{a}, \mathrm{B}}$ & $8.88^{\mathrm{a}, \mathrm{AB}}$ & $8.84^{\mathrm{a}, \mathrm{AB}}$ & $5.68^{\mathrm{b}}$ & $5.38^{\mathrm{b}}$ & 0.38 & $* * *$ \\
\hline & 240 & $8.70^{\mathrm{a}, \mathrm{B}}$ & $8.98^{\mathrm{a}, \mathrm{AB}}$ & $8.45^{\mathrm{a}, \mathrm{C}}$ & $6.08^{\mathrm{b}}$ & $5.09^{\mathrm{c}}$ & 0.36 & $* * *$ \\
\hline Significance & & $* *$ & $*$ & $* * *$ & ns & ns & & \\
\hline \multirow[t]{4}{*}{ Enterobacteriaceae } & 60 & 3.95 & $3.13^{\mathrm{A}}$ & 2.40 & $1.66^{\mathrm{B}}$ & 1.60 & 0.32 & ns \\
\hline & 120 & $4.26^{\mathrm{a}}$ & $3.62^{\mathrm{ab}, \mathrm{A}}$ & $2.08^{\mathrm{b}}$ & $3.96^{\mathrm{a}, \mathrm{A}}$ & $2.17^{\mathrm{b}}$ & 0.26 & $* *$ \\
\hline & 180 & $4.24^{\mathrm{a}}$ & $3.28^{\mathrm{ab}, \mathrm{A}}$ & $1.78^{\mathrm{b}}$ & $2.24^{\mathrm{b}, \mathrm{B}}$ & $2.45^{\mathrm{ab}}$ & 0.27 & $* *$ \\
\hline & 240 & 2.70 & $1.12^{\mathrm{B}}$ & 1.50 & $2.10^{\mathrm{B}}$ & 1.94 & 0.19 & $\mathrm{~ns}$ \\
\hline Significance & & ns & $* *$ & ns & $* * *$ & $\mathrm{~ns}$ & & \\
\hline
\end{tabular}

Different letters (a, b, c) in the same row indicate statistically significant differences. Different letters (A, B, C) in the same column indicate statistically significant differences (Tukey test $p<0.05$ )

$S E M$ standard error of mean, $n s$ non-significant differences

${ }^{*} p<0.05 ; * * p<0.01 ; * * *<0.001$

(LCFA, C15:0 to C18:3) content increased during refrigerated storage, reaching the highest values at day 240 (Table 3). The HP treatment applied did not affect the levels of total FFAs, SCFAs, MCFAs and LCFAs. Butyric acid (C4:0) was the most abundant FFA (data not shown). Butyric acid has a rancid cheese-like odour and plays an important role in the flavour of Torta del Casar cheese (Delgado et al. 2009). However, large amounts of butyric acid could be unpleasant. At day 240, concentration of butyric acid in HP-treated cheeses was lower than that found in control ones. Previous studies on ewe's milk cheeses produced different results showing an increase (Juan et al. 2007b) and a decrease (Calzada et al. 2014) in FFAs after HP treatment. Differences could be caused by the different HP treatments applied (pressure and holding time), the state of ripening of the pressurised cheeses or the characteristics of cheese (vegetable coagulant vs. rennet), among others. In line with our results, a study in full-fat Cheddar reported that total levels of FFAs in HP-treated cheeses at $400 \mathrm{MPa}$ for 10 min just after manufacture did not differ significantly from control cheeses over 180 days of ripening (Rynne et al. 2008). Similarly, no significant differences in FFA levels were observed between HP-treated mature blue-veined cheese at 400 and $600 \mathrm{MPa}$ for $10 \mathrm{~min}$ and control cheeses (Voigt et al. 2010). In Hispánico cheese, negligible differences in individual FFA levels compared to control were reported after treatment at $400 \mathrm{MPa}$ for 5 min (Ávila et al. 2007).

The levels of total FFAs increased during the refrigerated storage (Table 3). This increase in FFA content is in line with the results obtained in previous studies of ripening in this type of cheese (Delgado et al. 2009), in other ewe's raw milk cheeses using vegetable rennet such as La Serena cheese (Fernández-García et al. 2006) and 


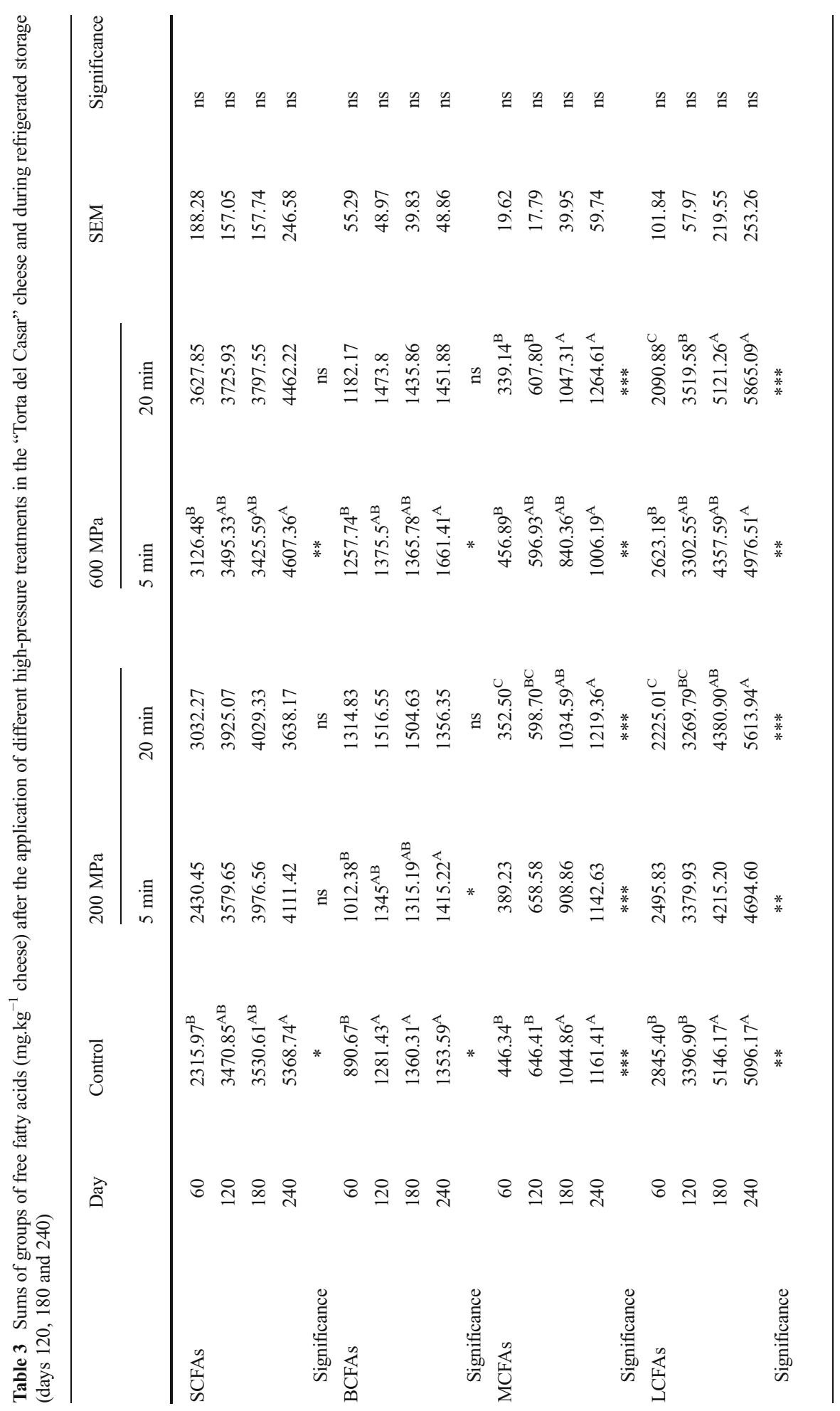




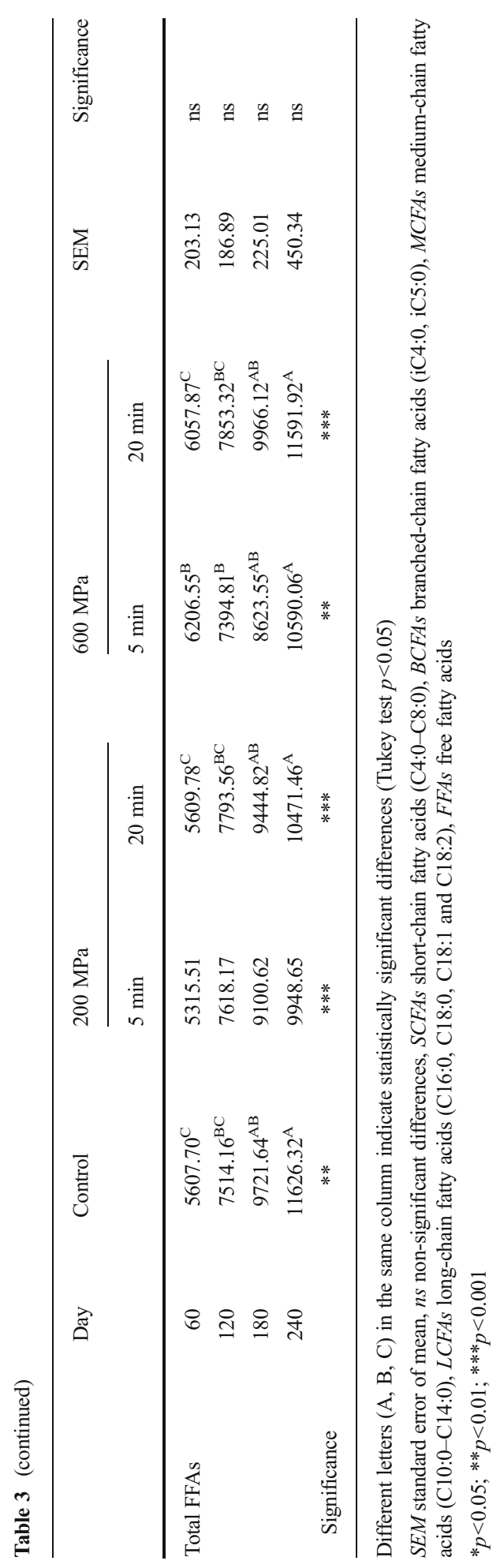


Serra da Estrela cheese (Macedo and Malcata 1996; Partidario et al. 1998) and in ewe's raw milk cheeses such as Idiazábal (Chávarri et al. 1999), Manchego and Zamorano cheeses (Fernández-García et al. 2006). In raw milk cheeses, indigenous milk lipases play the main role as lipolytic agents. However, microorganisms that are a part of the native microflora of raw milk cheeses contribute to cheese lipolysis due to intracellular lipolytic enzymes that are released into the cheese matrix on lysis. These enzymes are the responsible for the liberation of significant levels of fatty acids during ripening and storage time (McSweeney 2004; Collins et al. 2003).

SCFA and BCFA content significantly increased during storage in control and HPtreated cheeses at $600 \mathrm{MPa}$ for $5 \mathrm{~min}$. No significant differences were found for other HP treatments during storage. Total SCFA content increased 2.3-fold from day 60 to 240 in control cheeses and 1.5-fold from day 60 to 240 in cheeses treated at $600 \mathrm{MPa}$ for $5 \mathrm{~min}$. Lower values of SCFAs have been reported at day 240 in the same type of cheese treated at $600 \mathrm{MPa}$ for 5 min on day 35 of ripening (Calzada et al. 2014) obtaining significant lower values of SCFA in HP-treated cheeses compared to control. However, in 15-day-old Hispánico cheese pressurised at $400 \mathrm{MPa}$ for $5 \mathrm{~min}$, no significant differences were found in the concentration of SCFAs between HPP and control cheeses (Ávila et al. 2007). Similarly to our results, after a long-term storage (day 270), no significant differences were found in SCFA concentrations in blue-veined cheese treated at $600 \mathrm{MPa}$ for $5 \mathrm{~min}$ at day 63 of ripening compared to control cheese (Calzada et al. 2013).

On the other hand, MCFA content was significant influenced by storage time in control and pressurised cheeses, showing highest levels at day 240 (Table 3). MCFA content in control cheeses increased 2.6-fold from day 60 to day 240. Similar rates have been previously reported for this cheese which showed a MCFA concentration that increased 2.3-fold from day 60 to 240 of storage (Calzada et al. 2014). HP treatment did not affect the content of MCFAs, and similar values were obtained in control and HPtreated cheeses. Our results agree with the reported in blue-veined cheese, which showed no significant differences in MCFA concentrations between cheeses treated at $600 \mathrm{MPa}$ for $5 \mathrm{~min}$ at day 63 of ripening and control cheeses after 270 days of storage (Calzada et al. 2013). Similar results have also been found in raw goat's milk cheese which showed non-significant differences in MCFA concentrations on day 60 between pressurised and control cheeses (Delgado et al. 2012).

Storage time significantly affected the LCFA content in control and pressurised cheeses (Table 3). Similarly to the results obtained for SCFAs and MCFAs, no significant differences in LCFA content were found between control and HP-treated cheeses. In line with our results, the levels of LCFA of blue cheese pressurised at $600 \mathrm{MPa}$ for $5 \mathrm{~min}$ at day 63 of ripening did not differ from control cheeses at day 270 of storage (Calzada et al. 2013).

\section{Conclusions}

Microbial groups analysed in Torta del Casar cheese were affected by HPP. Results indicate that Enterobacteriaceae counts decreased after HP treatment in the interior of the cheese, increasing the food safety of Torta del Casar raw ewe's milk cheese. The maintenance of the plastic bag used for HPP during the subsequent refrigerated storage 
of cheese might be sufficient to avoid the incidence of defects on the rind of this cheese, but prevention of colour changes in cheese rind should be further studied. The inactivation of microorganisms did not affect the FFA levels during storage. The levels of most FFAs were not affected by HPP showing similar values of FFAs in control and HPP cheeses. However, the reduction in the levels of important SCFAs in HP-treated cheeses compared to control ones, such as the butyric acid, could have effects on cheese flavour during the long-term storage, avoiding the formation of over-ripened aromas which are rejected by the consumers.

Acknowledgments This study has been financed by the project RITECA II and cofinanced by the Consejería de Empleo, Empresa e Innovación of the Gobierno de Extremadura, by the European Regional Development Fund (ERDF) and by the Programa Operativo de Cooperación Transfronteriza España-Portugal (POCTEP; 2007-2013).

Compliance with ethics guidelines This article does not contain any studies with human or animal subjects performed by any of the authors.

\section{References}

Arqués JL, Rodríguez E, Gaya P, Medina M, Guamis B, Núñez M (2005a) Inactivation of Staphylococcus aureus in raw milk cheese by combinations of high-pressure treatments and bacteriocin-producing lactic acid bacteria. J Appl Microbiol 98:254-260

Arqués JL, Rodríguez E, Gaya P, Medina M, Núñez M (2005b) Effect of combinations of high pressure treatments and bacteriocin-producing lactic acid bacteria on the survival of Listeria monocytogenes on raw milk cheese. Int Dairy J 15:893-900

Arqués JL, Garde S, Gaya P, Medina M, Núñez M (2006) Short communication: inactivation of microbial contaminants in raw milk La Serena cheese by high-pressure treatments. J Dairy Sci 89:888-891

Ávila M, Calzada J, Garde S, Nuñez M (2007) Effect of a bacteriocin-producing Lactococcus lactis strain and high-pressure treatment on the esterase activity and free fatty acids in Hispánico cheese. Int Dairy J 17 : 1415-1423

Balasubramaniam VM, Farkas D, Turek EJ (2008) By destroying pathogenic and spoilage organisms while keeping food chemistry basically intact, high pressure technology enables pasteurization of foods with minimal effects on taste, texture, appearance, or nutritional value. Food Technol 11:32-38

Calzada J, Del Olmo A, Picon A, Gaya P, Nuñez M (2013) High-pressure processing decelerates lipolysis and formation of volatile compounds in ovine milk blue-veined cheese. J Dairy Sci 96:1-11

Calzada J, Del Olmo A, Picon A, Gaya P, Nuñez M (2014) High-pressure processing for the control of lipolysis, volatile compounds and off-odours in raw milk cheese. Food Bioprocess Technol 7:2207-2217

Chávarri F, Bustamante MA, Santisteban A, Virto M, Barron LJR, Renobales M (1999) Changes in free fatty acids during ripening of Idiazabal cheese manufactured at different times of the year. J Dairy Sci 82:885-890

Collins YF, McSweeney PLH, Wilkinson MG (2003) Lipolysis and free fatty acid catabolism in cheese: a review of current knowledge. Int Dairy J 13:841-866

De Jong C, Badings HT (1990) Determination of free fatty acids in milk and cheese. Procedures for extraction, clean up and capillary gas chromatographic analysis. J High Res Chromatogr 13:94-98

Delgado FJ, González-Crespo J, Ladero L, Cava R, Ramírez R (2009) Free fatty acids and oxidative changes of a Spanish soft cheese (Torta del Casar) during ripening. Int J Food Sci Technol 44:1721-1728

Delgado FJ, González-Crespo J, Cava R, Ramírez R (2012) High-pressure treatment applied throughout ripening of a goat cheese caused minimal changes on free fatty acids content and oxidation in mature cheese. Dairy Sci Technol 92:237-248

Fernández del Pozo B, Gaya P, Medina M, Rodríguez-Marín MA, Nuñez M (1988) Changes in the microflora of La Serena ewes' milk cheese during ripening. J Dairy Res 55:449-455

Fernández-García E, Carbonell M, Calzada J, Nuñez M (2006) Seasonal variation of the free fatty acids contents of Spanish ovine milk cheeses protected by a designation of origin: a comparative study. Int Dairy J 16:252-261

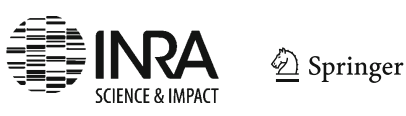


Hernández I, Barrón LJR, Virto M, Pérez-Elortondo FJ, Flanagan C, Rozas U, Nájera AI, Albisu M, Vicente MS, Renobales M (2009) Lipolysis, proteolysis and sensory properties of ewe's raw milk cheese (Idiazabal) made with lipase addition. Food Chem 116:158-166

Juan B, Ferragut V, Guamis B, Buffa M, Trujillo AJ (2004) Proteolysis of a high pressure-treated ewe's milk cheese. Milchwissenschaft 59:616-619

Juan B, Ferragut V, Buffa M, Guamis B, Trujillo AJ (2007a) Effects of high pressure treatment on free fatty acids release during ripening of ewes' milk cheese. J Dairy Res 74:438-445

Juan B, Barron LJ, Ferragut V, Guamis B, Trujillo AJ (2007b) Changes in the volatile composition of a semihard ewe milk cheese induced by high-pressure treatment of $300 \mathrm{MPa}$. J Agric Food Chem 55:747-754

Juan B, Ferragut V, Guamis B, Trujillo AJ (2008) The effect of high pressure treatment at $300 \mathrm{MPa}$ on ripening of ewes' milk cheese. Int Dairy J 18:129-138

Macedo AC, Malcata FX (1996) Changes in the major free fatty acids in Serra da Estrela cheese during ripening. Int Dairy J 6:1087-1097

Martínez-Rodríguez Y, Acosta-Muñiz C, Olivas GI, Guerrero-Beltrán J, Rodrigo-Aliaga D, Sepúlveda DR (2012) High hydrostatic pressure processing of cheese. Compr Rev Food Sci F11:399-416

McSweeney PLH (2004) Biochemistry of cheese ripening. Int J Dairy Technol 57:127-144

McSweeney PLH, Sousa MJ (2000) Biochemical pathways for the production of flavour compounds in cheese during ripening. Lait 80:293-324

Partidario AM, Barbosa M, Vilas-Roas L (1998) Free fatty acids, triglycerides and volatile compounds in Serra da Estrela cheese - changes during ripening. Int Dairy J 8:873-881

Rodríguez E, Arqués JL, Núñez M, Gaya P, Medina M (2005) Combined effect of high pressure treatments and bacteriocin-producing lactic acid bacteria on the inactivation of Escherichia coli $\mathrm{O} 157: \mathrm{H} 7$ in raw milk cheese. Appl Environ Microbiol 71:3399-3404

Rynne NM, Beresford TP, Guinee TP, Sheehan E, Delahunty CM, Kelly AL (2008) Effect of high-pressure treatment of 1 day-old full-fat Cheddar cheese on subsequent quality and ripening. Innov Food Sci Emerg Technol 9:429-440

Voigt DD, Chevalier F, Qian MC, Kelly AL (2010) Effect of high-pressure treatment on microbiology, proteolysis, lipolysis and levels of flavour compounds in mature blue-veined cheese. Innov Food Sci Emerg Technol 11:68-77 